\title{
BMJ Open Experiences of living with developmental dysplasia of the hip in adults not eligible for surgical treatment: a qualitative study
}

\author{
Martin Dan Jorgensen (1D , ${ }^{1}$ Sarah Bournonville Frederiksen 다 , ${ }^{1}$ Dorthe Sørensen, ${ }^{2}$ \\ Julie Sandell Jacobsen (1) ${ }^{2,3}$
}

To cite: Jorgensen MD, Frederiksen SB, Sørensen D, et al. Experiences of living with developmental dysplasia of the hip in adults not eligible for surgical treatment: a qualitative study. BMJ Open 2021;11:e052486. doi:10.1136/ bmjopen-2021-052486

- Prepublication history and additional supplemental material for this paper are available online. To view these files, please visit the journal online (http://dx.doi.org/10.1136/ bmjopen-2021-052486).

MDJ and SBF contributed equally.

Received 16 April 2021 Accepted 09 December 2021

Check for updates

(c) Author(s) (or their employer(s)) 2021. Re-use permitted under CC BY-NC. No commercial re-use. See rights and permissions. Published by BMJ.

'Department of Physiotherapy, VIA University College, Aarhus N, Denmark

${ }^{2}$ Research Centre for Health and Welfare Technology, Programme for Rehabilitation, VIA University College, Aarhus N, Denmark

${ }^{3}$ Research Unit for General Practice, Aarhus, Denmark

Correspondence to Mr Martin Dan Jorgensen; martin.dan@get2net.dk

\section{ABSTRACT}

Objectives Adults with developmental dysplasia of the hip face barriers in their everyday lives due to pain and physical limitations. In Denmark, some patients may not be eligible for hip-preserving surgery due to being overweight, hip osteoarthritis, age above 45 years, negative impingement test or not wishing to undergo surgery. These patients are left with no evidence-based treatment option. The patient perspective when not being eligible for surgery has not yet been investigated. This study aimed to explore the experiences of living with developmental dysplasia of the hip in adults not eligible for hip-preserving surgery.

Design and participants In this qualitative study, we used a phenomenological-hermeneutic approach to explore the experiences of living with developmental dysplasia of the hip. We conducted semistructured interviews with 17 purposefully selected patients (median age 37 (range 19-50) years). The patients were recruited from a population of 30 patients included in a larger feasibility study evaluating a 6-month exercise and patient education intervention. We used a ricoeur-inspired method to analyse and interpret the interview data.

Results Three themes were identified. First,

developmental dysplasia of the hip is more than just a joint disease. Second, living with pain is difficult when pain has its own life. Third, limitations imposed by hip problems challenge the perception of oneself as young, active and independent. Identity, meaningfulness, control over pain and coping with pain were areas of the patients' lives that were influenced.

Conclusion Living with developmental dysplasia of the hip had a considerable impact on the patients of this study and their everyday life in several areas. Therefore, it may be relevant to approach patients with developmental dysplasia of the hip from a biopsychosocial point of view. However, further research is required to obtain a better understanding of the experiences of living with developmental dysplasia of the hip.

\section{INTRODUCTION}

Developmental dysplasia of the hip (DDH) is a common hip disease, which is characterised by reduced acetabular coverage of the femoral head. ${ }^{1}$ DDH generally affects infants
Strengths and limitations of this study

- The phenomenological-hermeneutic approach offered an excellent opportunity to explore the experiences of living with developmental dysplasia of the hip.

- The interdisciplinary research team fostered broad perspectives on the collected data.

- As the study was embedded in a feasibility study, the interview questions mainly revolved around the patients' perception of current everyday life.

- A limitation was that the interviews were primarily conducted by telephone.

and children; however, DDH also affects adults in early working age, the majority of whom are women. ${ }^{23}$ Throughout life, adult patients with DDH face barriers in their everyday activities, such as impaired walking, running, standing and prolonged sitting, due to daily pain and low physical function. ${ }^{45}$ Both pain and physical function may be improved by hip-preserving surgery, a periacetabular osteotomy (PAO) ${ }^{367}$ However, in Denmark, some patients may not be eligible for hip-preserving surgery due to being overweight (body mass index $(\mathrm{BMI})>25),{ }^{8}{ }^{9} \mathrm{hip}$ osteoarthritis (OA), ${ }^{9}$ age above 45 years, ${ }^{9} 10$ negative impingement test ${ }^{10}$ or not wishing to undergo surgery for personal reasons. These patients are, therefore, left with no evidence-based treatment option. Exercise interventions could be an alternative to hippreserving surgery. The evidence for exercise interventions is, however, sparse. Only two studies have investigated the outcome of short-term interventions. ${ }^{11} 12$ The results of one study showed improved pain and hip muscle strength after 3 months of hip abductor strengthening. ${ }^{11}$ A second study showed improved pain, patient-reported outcomes and functional performance after 
8 weeks of progressive resistance training. ${ }^{12}$ However, in these two studies, some potential participants were excluded because they were categorised as being overweight and/or had manifest OA (Tönnis OA score $>1$ ). This limits the generalisability of the results and indicates a research gap concerning adults with DDH who are not eligible for hip-preserving surgery.

Adherence is a key factor for treatment success, and the importance of adherence should be considered in the planning of an intervention. ${ }^{13}$ Adherence has been linked to patients' understanding and experience of their disease, which underlines the importance of giving them the opportunity to tell their story regarding their beliefs, attitudes, behaviours, expectations and perceptions of self. ${ }^{14}$ Few studies have examined patients' experiences of living with $\mathrm{DDH}$, reporting that patients were negatively affected in terms of their identity, body image, quality of life and psychosocial well-being. ${ }^{15-17}$ Furthermore, in order to cope with pain, patients used different strategies, for example, changing their lifestyle or adapting their activities. ${ }^{15-17}$ Psychological factors, such as pain catastrophisation, anxiety and depression, have also been found present in some patients with persistent hip pain, including patients with DDH. ${ }^{18-21}$ Previous studies on patients' experiences of living with daily joint pain have additionally reported that patients' sense of symptoms and their beliefs about pain were closely related to coping response, pain management and activity avoidance. ${ }^{22} 23$

However, no previous studies have explored patients' experiences of living with DDH when not being eligible for hip-preserving surgery. Therefore, this study aimed to explore the experiences of living with DDH in adults who are not eligible for hip-preserving surgery.

\section{METHODS}

\section{Study design}

This qualitative study used a phenomenological-hermeneutic approach, inspired by Paul Ricoeur, ${ }^{24}{ }^{25}$ to explore the experiences of living with DDH. We obtained qualitative data on 17 patients with DDH as part of a larger feasibility study evaluating a 6-month exercise and patient education intervention in adults not eligible for hippreserving surgery (unpublished). The qualitative data for this study were collected before the intervention through semistructured interviews.

The 32-item Consolidated Criteria for Reporting Qualitative Research (COREQ) were used to ensure methodological rigour. ${ }^{26}$ Regular research meetings were held to discuss the data analysis, sampling methods and data generation.

The research team included one male and three female researchers; two physiotherapists (MDJ and SBF) and two active clinical researchers, each holding a $\mathrm{PhD}$ degree, one registered nurse with expertise in qualitative designs (DS) and one physiotherapist (JSJ).
Box 1 Eligibility criteria for participation in a feasibility study evaluating a 6-month exercise and patient education intervention

Inclusion criteria

1. $18-50$ years of age.

2. Radiographically verified DDH by Wiberg's centre edge angle between $10^{\circ}$ and $25^{\circ 40}$ and an acetabular index angle $>10^{\circ} .{ }^{41}$

3. Groin and/or hip pain for a minimum of 3 months.

4. Not eligible for PAO due to negative impingement test, $\mathrm{BMI}>25$, hip $\mathrm{OA}$, age $>45$ years, reduced hip range of motion, and/or no wish to undergo surgery.

Exclusion criteria

1. Planned arthroplastic hip surgery.

2. $\mathrm{BMl}>35$.

3. Acetabular retroversion defined by crossover sign and posterior wall sign.

4. Legg-Calvé-Perthes disease or epiphysiolysis.

5. Previous pelvic surgery in index limb.

6. Previous pelvic surgery within 2 years in contralateral limb.

7. Previous surgery due to herniated disc or spondylodesis.

8. Previous arthroplastic surgery in the hip, knee or ankle.

9. Physical (pregnancy/trauma), neurological, medical or rheumatic conditions severely affecting the hip function.

10. Inadequacy in written and spoken Danish, mental health issues or other conditions affecting the ability to follow mandatory procedures for participation.

\section{Recruitment}

Patients with DDH were assessed for eligibility for the larger feasibility study, and, thus, also this qualitative study, at the Department of Orthopaedic Surgery at Aarhus University Hospital, Denmark, from January 2020 to August 2020. Orthopaedic surgeons screened patients for eligibility (see box 1), provided written information and asked patients for permission to be contacted by author JSJ. Author JSJ provided oral information, and after 1 week of reflection, patients agreeing to participate gave informed consent and were enrolled in the feasibility study.

The reasons for including or excluding patients in the larger feasibility study were as follows. Patient age was defined as 18-50 years, since exercise interventions for adults above 50 years have been developed and proven effective. ${ }^{27}$ The lower BMI threshold was set to 25 as the exercise intervention was developed for patients who were not eligible for PAO if their BMI was above $25 .{ }^{8}$ The higher BMI threshold was set to 35 as patients with BMI above 35 typically experience other and more barriers to exercise than patients with a lower BMI. ${ }^{28}$ Patients who had undergone previous surgery were excluded since the outcome of previous surgery may affect their ability to exercise. Patients were also excluded if pregnant, since birth or pregnancy would affect outcomes at the 6-month follow-up.

Patients from the larger feasibility study were then purposefully sampled to participate in semistructured interviews for this qualitative study. ${ }^{29}$ To ensure a wide 


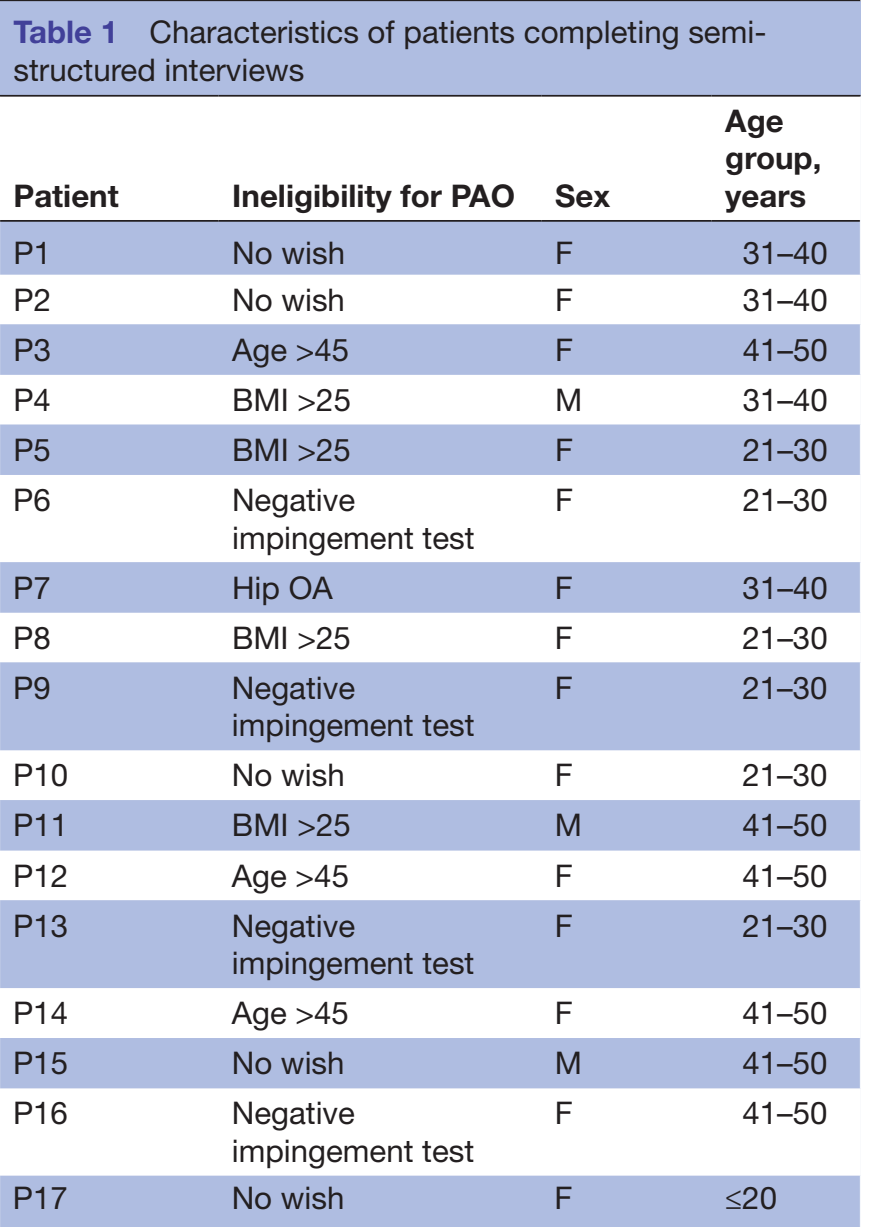

BMI, body mass index; OA, osteoarthritis; PAO, periacetabular osteotomy.

range of characteristics, patients were sampled across sex, age, pain level and reason for not being eligible for PAO. The sample size for this qualitative study was not predicted before the study was conducted, and the sampling procedure continued until the analysis added no new insights. ${ }^{30}$ Seventeen patients were interviewed for this study out of 30 eligible patients from the feasibility study.

The Copenhagen Hip and Groin Outcome Score (HAGOS) was completed by the patients. ${ }^{31}$ HAGOS is a disease-specific questionnaire, which was developed to measure self-reported outcomes in young to middle-aged patients with hip and/or groin pain on a score ranging from 0 to 100 . The median scores for the patients on the six HAGOS subscales were as follows: symptoms $=50$ points (range $25-86$ points), pain $=55$ points (range $30-90$ points), function in daily living $=65$ points (range 20-95 points), function in sport and recreation $=34$ points (range 3-100 points), participation in physical activities $=38$ points (range $0-100$ points) and hip and/ or groin-related quality of life $=40$ points (range 5-65 points). Other important characteristics were reported separately for each patient (see table 1). The present study included 14 women and 3 men with a median age of 37 years (range $19-50$ years).

\section{Ethical considerations}

This study complies with the Helsinki Declaration. ${ }^{32}$ The patients were informed of goals and reasons for doing the research, and written consent was obtained from all patients. All were informed that participation was voluntary and that they could withdraw from the study at any time.

Complete anonymity was ensured for the patients. The research team had no contact with the patients before the start of this study.

\section{Patient and public involvement}

Four patients (one man) were involved in the planning and design of the larger feasibility study, including this qualitative study. Regular meetings were held, where the patients' experiences and perceptions of DDH and expectations for participation were discussed. The outcome of these meetings was incorporated in the development of the interview guide used in this study.

\section{Data collection}

Semistructured interviews, guided by a phenomenological-hermeneutic approach, were conducted from January 2020 to August 2020 by author JSJ, who has extensive knowledge of patients with DDH. The interviews were completed in a quiet room at Aarhus University Hospital, either face-to-face $(n=5)$ or by telephone $(n=12)$ according to the individual patient's preference. ${ }^{33}$ The interviews were based on a semistructured interview guide developed by authors DS and JSJ (see online supplemental appendix 1).

The interview guide contained questions about the patient's everyday life, experiences with their condition, pain, sports and leisure activities and successes with goal setting. Questions were primarily open ended, such as 'How would you describe your everyday life?', 'What would you like to be able (do you dream of being able) to do?' and 'What adds value or brings joy in your everyday life?'.

The interviews lasted on average 20 min (maximum: $26 \mathrm{~min}$ ). All interviews were recorded by a built-in smartphone app. Recorded interviews were transcribed verbatim into Word by authors MDJ and SBF.

\section{Analysis}

The interviews were analysed by authors MDJ and SBF and guided by Dreyer and Pedersen's Ricoeur-inspired analysis, moving from what the text says to what it speaks about. The analysis consists of three levels: a naive reading, a structured analysis and a critical analysis and discussion. ${ }^{25}$

For a preliminary analysis, the authors read the complete text (ie, naive reading). During this first phase, thoughts were formulated about the text's meaning for further structural analysis. In the structured analysis, moving from what the text says to what it speaks about, patterns were identified, and connections led to the identification of three themes (see table 2). Throughout this 


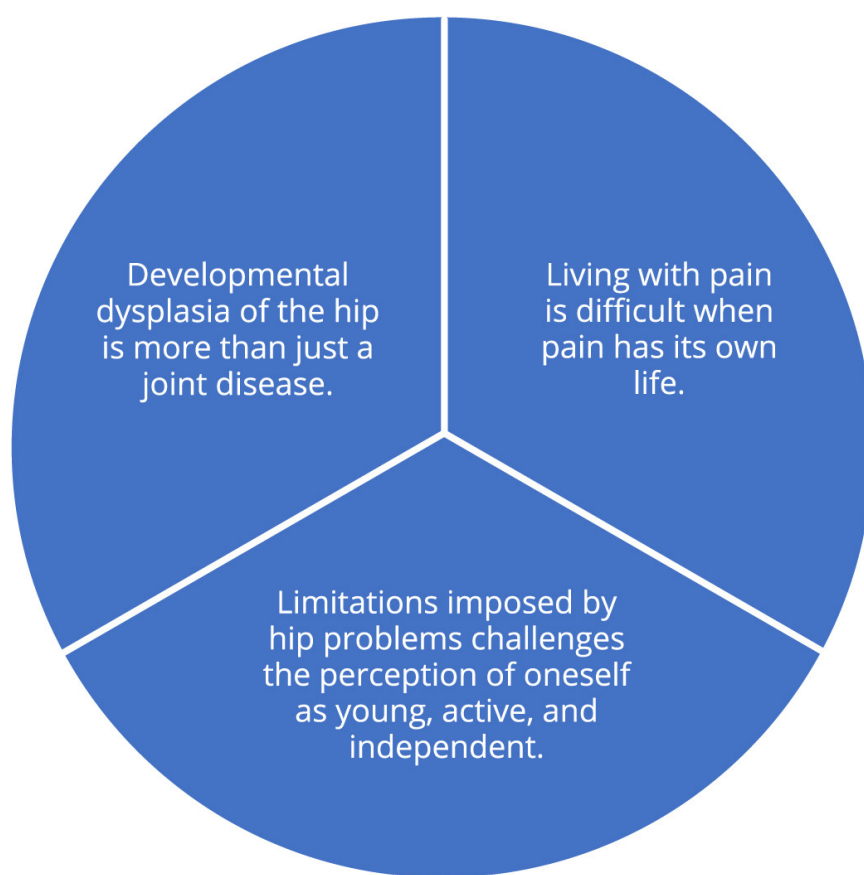

Figure 1 Three themes of the experiences of living with developmental dysplasia of the hip.

process, the research team was conscious of their preunderstanding, bringing awareness to the subjective interpretations of the text by meeting several times to discuss their preunderstanding of the emerging themes. Finally, for the critical analysis, the themes were discussed in the light of relevant literature.

The patients were not asked to validate the interview transcripts because we anticipated that their reflective answers would develop during the interview. Quotes from the interviews are used to support claims and illustrate the identified themes.

\section{RESULTS}

Three themes were derived from the data during analysis (see figure 1). First, DDH is more than just a joint disease. Second, living with pain is difficult when pain has its own life. Third, limitations imposed by hip problems challenge the perception of oneself as young, active and independent. For each of the three themes, patterns have been identified, and these patterns contribute to describing the themes (see table 3 ).

\section{Theme 1: DDH is more than just a joint disease}

The patients experienced a lack of knowledge of their disease. Besides knowing the morphological development of the hip joint, that is, how 'the hip socket and the head of the hip bone don't quite fit together' (P1), they lacked understanding of the increased demand on the hip muscles due to the dysplastic hip joint. One patient was aware of the increased stress placed on the acetabular labrum and the associated risk of OA. However, since she was not eligible for $\mathrm{PAO}$, she believed that her only option was to endure the pain. Others had minimal knowledge: 
Table 3 Themes reflecting the experiences of living with developmental dysplasia of the hip

\begin{tabular}{|c|c|}
\hline Themes & Identified patterns \\
\hline $\begin{array}{l}\text { Developmental dysplasia of } \\
\text { the hip is more than just a } \\
\text { joint disease }\end{array}$ & $\begin{array}{l}\text { Understanding of disease } \\
\text { Medical history } \\
\text { Earlier treatment } \\
\text { Movements associated with } \\
\text { pain } \\
\text { Activity limitations } \\
\text { Quality of sleep } \\
\text { Emotional well-being }\end{array}$ \\
\hline $\begin{array}{l}\text { Living with pain is difficult } \\
\text { when pain has its own life }\end{array}$ & $\begin{array}{l}\text { Unpredictability of pain } \\
\text { Control over pain } \\
\text { Coping behaviours } \\
\text { Perception of pain }\end{array}$ \\
\hline $\begin{array}{l}\text { Limitations imposed by } \\
\text { hip problems challenges } \\
\text { the perception of oneself } \\
\text { as young, active and } \\
\text { independent }\end{array}$ & $\begin{array}{l}\text { Meaningful activities } \\
\text { Impact on identity } \\
\text { Hopes and dreams } \\
\text { Adjusting expectations } \\
\text { Self-efficacy }\end{array}$ \\
\hline
\end{tabular}

'I only know what I have found out by googling ... and I don't know if it's something I should be nervous about' (P2).

Prior to diagnosis, they suspected that their hip pain was caused by an overload or an overuse injury. They were pleased to get the correct diagnosis as they thought that they were 'doing something wrong or hadn't stretched out enough or something else' (P3). Over the years, they had tried numerous treatment modalities, such as physiotherapy, chiropractic treatment, exercises, yoga, massage therapy and magnetic therapy.

The patients experienced hip pain mostly during prolonged periods of sitting or standing, or during walking, running, climbing stairs, heavy lifting or activities involving end-range positions. Poor sleep was also an issue for many patients, as they had to change sleeping positions regularly during the night due to pain. For several patients, hip pain reduced their ability to participate in sports and physical activities. However, they were still able to do activities of daily living despite their pain. Others were more disabled and were limited in both daily and work-related activities. They experienced that their physical function and daily resources were critically reduced. This was expressed in different ways, ranging from feeling that the disease is 'always with me' (P2) to brief moments of forgetting about the disease during physical activity:

It's almost as if I'm limited in everything I do for 23 hours a day, and then when I go and play paddle tennis for an hour, I'm like, 'oh, unbelievable, I can do this when... I can't even sit in a car, and I can't walk (P4).

The patients were also affected emotionally by minor mood changes, expressing general irritation and frustration toward their situation. In addition, being limited in physical activities restricted them from having meaningful social relationships:

I had an extremely active social life in football. I'm cut off from that a bit because I can't participate. I find that a bit hard on my mental health sometimes (P5).

They have gone through a challenging process of accepting their situation. Specifically, regarding their treatment options, it was hard to accept not being eligible for PAO. However, the decision whether or not to have surgery was also challenging, suggesting that both situations were difficult.

\section{Theme 2: living with pain is difficult when pain has its own life}

Pain was often experienced by the patients as unpredictable, almost as having a life of its own. When present, pain could vary in intensity. One patient, severely affected by her pain, explained, 'it feels like 10000 knives stabbing in my bones' (P6). They 'saw no pattern' (P7) in their pain. Therefore, many found it difficult to pace their activities. For some, pain could present 'out of the blue' (P8). This left them with a sense of loss of control over their pain, almost like being stuck in 'a vicious cycle' (P5). Thus, they sought ways of finding certainty in the uncertainty of their pain:

I think it would be absolutely amazing if I could just see a clearer pattern in when something hurts and when it doesn't hurt. ...And maybe if I could somehow get some tools to manage... or something I can do myself before it starts to really hurt (P9).

In general, the patients experienced that moderate activity and movement relieved pain. However, some cases required the patients to rest and use analgesics to relieve pain.

The patients had different ways of coping with their pain. These ranged from completely avoiding painful physical activities (in order to endure pain in their necessary everyday activities) to taking a more adaptive approach and avoiding activities that were known to provoke pain while remaining physically active (by doing different activities, adjusting activities or taking short breaks). Sometimes they actively chose to endure pain because they found the activity meaningful, knowing that the pain might flare up later.

The patients did not perceive their pain as dangerous, but rather as discomforting, considering how many found that they 'could endure most pain, but it's just not pleasant' (P9). However, some patients were noticeably worried about the nature or course of their disease:

I get worried when I get very severe pain where I can't use my legs. Because I'm afraid that it won't go away, and I will lose the ability to walk. Fortunately, it's not always that bad, and it always goes away quickly again. But I get worried about my future (P8). 
This illustrated an uncertainty concerning future pain appearing when having no evidence-based treatment option available.

\section{Theme 3: limitations imposed by hip problems challenges the} perception of oneself as young, active and independent

Being impaired by DDH had taken away the joy of many meaningful activities for the patients, including running, long walks and competing in sports like handball and football. Furthermore, many patients experienced that this affected their identity negatively and eroded the image of themselves as young, active and independent individuals.

Hence, many patients struggled with identifying themselves with their present age: 'I feel like an old woman who can't handle going for a short walk. I feel older than I really should' (P10).

They perceived that their physical function did not match that of their friends or colleagues of the same age. One patient said, 'it's totally absurd that a man in his forties isn't able to go for a walk' (P4).

Furthermore, sport and physical activity used to be an important part of the patients' lives. However, hip pain had forced them to quit or reduce their level of participation, which often resulted in a challenging process of managing everyday life with much less participation:

I have always been extremely physically active, but now I'm always the one watching from the sideline. It's really frustrating $(\mathrm{P} 4)$.

Nevertheless, some patients accepted their current situation and lived a normal everyday life, having 'reconciled with the fact that I shouldn't run because I can do other things' (P7).

Moreover, some patients emphasised the difficulties of being dependent on others:

It bothers me a lot because I'm a woman who can and wants to get by on my own. The more I can do myself, the better. I don't feel like I can do everything that I want to right now (P6).

The patients were particularly bothered that their impairments were visible to others, for example, having a limped gait, resulting in 'a skewed picture of how I really should be' (P8).

The patients also shared concerns about their future. They longed for being completely pain free. However, they questioned the possibility of this and adjusted their expectations, hoping for a future where their pain would at least not restrict them. For those patients who had declined surgery, it seemed vital to postpone or completely avoid surgery in the future. They displayed a high level of self-efficacy, especially towards exercise, believing in their ability to achieve 'a good, healthy, and strong hip' (P11). However, they expressed a need for professional support in adjusting exercise and more autonomy in handling their situation.
The results indicate how the patients experienced that the pain considerably influenced their everyday life. This was specifically shown in terms of control over pain, coping with pain, changes in meaningful activities and their selfperception of being young, active and independent.

\section{DISCUSSION}

In this study, patients with DDH experienced that: (1) DDH is more than just a joint disease, (2) living with pain is difficult when pain has its own life and (3) limitations imposed by hip problems challenge the perception of oneself as young, active and independent. They found that their pain was unpredictable, which made it difficult for them to pace their activities and made them feel that they had lost control over the pain. However, the patients also insisted on continuing their everyday life activities, which they managed by resorting to different coping strategies like avoiding, adapting and enduring. Still, many were forced to quit or reduce their meaningful activities due to hip pain. Furthermore, the hip problems also negatively affected their perception of themselves as young, active and independent individuals. Ultimately, the patients adjusted their expectations to their future and questioned whether becoming completely free of pain would be realistic.

Our study is the first to explore the experiences of living with DDH in a population of adults not eligible for hip-preserving surgery. Other qualitative studies examining patients with DDH have mostly focused on patients undergoing PAO. ${ }^{15-17}$ Therefore, this study adds to the existing literature by providing new insight that should be considered when planning exercise interventions for patients with DDH. Nevertheless, in line with our study, previous qualitative studies have shown that patients with DDH experience that their identity and emotional wellbeing are negatively affected and that they need to use different coping strategies to manage daily pain. ${ }^{15-17}$ We also found that patients with DDH experienced problems during walking, sitting, sleeping and other vital functions of everyday life. In line with our study, other studies have found that DDH is associated with gait impairments, ${ }^{34}$ muscle strength deficits, ${ }^{35}$ reduced function in daily living ${ }^{4}$ and poor sleep quality. ${ }^{196}$ Additionally, other studies have reported frequent traits of anxiety and depression in patients with DDH. ${ }^{18-21}$ In contrast, our data showed that patients' emotional well-being was affected only to a moderate extent in the form of minor mood changes. However, this additional impact on emotional well-being beyond the physical impairments of the disease emphasises the importance of recognising biopsychosocial factors in the management of DDH. This was also suggested in a recent qualitative study of patients with persistent hip pain disorders. ${ }^{23}$

Recent discoveries have shown that DDH is partly related to muscle-tendon structures around the hip. ${ }^{37}$ Hence, 'the understanding of hip dysplasia as solely a joint disease should perhaps be reconsidered'. ${ }^{37}$ 
Consequently, patients' knowledge of DDH may need to expand beyond the hip joint to involve the role of the musculature around the joint. Other qualitative studies have also identified different coping strategies in patients with DDH. ${ }^{15-17}$ One study reported that it could be difficult to cope with the disease, both physically and psychologically. ${ }^{15}$ Our results on identity are supported by other studies, which also found a considerable impact on identity in their population of patients with DDH, although this was mainly explained by the impact on key developmental milestones in young adults. ${ }^{15-17}$ In the light of previous results and the results of the present study, patients' experiences should be considered when treating patients with DDH.

\section{Strengths and limitations of the study}

The phenomenological-hermeneutic approach adopted in this qualitative study offered an excellent opportunity to explore the experiences of living with DDH. By discussing the emerging themes in the analysis among our interdisciplinary research team, spanning the fields of nursing and physiotherapy, we achieved broad perspectives on the data and valid interpretations. Additionally, our phenomenological-hermeneutic approach implied that we were conscious of our preunderstanding of the subject, which ensured that our clinical backgrounds did not negatively influence our interviews or analysis, but rather strengthened them. However, this study also had limitations. As our data came from a feasibility study, the interview questions primarily concerned the patients' current everyday life and activities. The interviews were conducted during the COVID-19 pandemic. Therefore, for safety, the majority of patients chose telephone interviews. This might have influenced the quality of the interviews. Nevertheless, as a data collection method, the telephone interview is a reasonable tool unlikely to influence the depth of the interviews. ${ }^{33} 38$ Finally, this study population was relatively homogenous due to being recruited from the feasibility study; and some nuances of the lived experience of DDH might, therefore, have been missed. All patients were also recruited from the same hospital ward, possibly causing a selective sample of patients. However, the results may still be generalisable to other groups of patients with DDH, specifically considering the comparable findings reported in other studies of similar populations. ${ }^{15-17}$

\section{Implications for clinical practice}

The results of this study reveal that the patients lacked knowledge about their disease, they found it difficult to pace their activities, and they felt that the disease had a negative impact on their meaningful daily activities. Nevertheless, they also had high self-efficacy for exercising. Overall, it should be considered if patients may benefit from patient education when exercise interventions are planned, as this may expand their knowledge of DDH. Furthermore, activity modification may be discussed with the patients to help them better pace their activities and participate in meaningful activities. Some patients may experience frustration and irritation due to their physical limitations. The physical limitations could also negatively affect their perception of their own identity. Thus, it seems relevant to approach patients with DDH from a biopsychosocial point of view. This is supported by a recent literature review exploring non-operative management of individuals with non-arthritic hip pain (ie, femoroacetabular impingement, labral tears and DDH). This review highlighted the advantage of using an approach based on patient education, activity modification and exercise. $^{39}$

\section{CONCLUSION}

Living with DDH had a considerable impact on the patients of this study and their everyday lives in several areas of identity, meaningfulness, control over pain and coping with pain. Therefore, it may be relevant when treating patients with DDH to consider their experiences of living with their disease, and approach these patients from a biopsychosocial point of view. However, further research is required to obtain a better understanding of the experiences of living with DDH.

\section{Twitter Julie Sandell Jacobsen @JulieS_Jacobsen}

Acknowledgements The authors would like to thank all participating patients for taking part in the study.

Contributors MDJ and SBF contributed equally to this work (joint first authorship) by drafting the manuscript and making all the qualitative analyses. DS and JSJ designed the study and were involved in drafting and reviewing the manuscript, and JSJ additionally facilitated participant recruitment. All authors critically reviewed, edited, and approved the final manuscript, and all authors take responsibility for the integrity and accuracy of the data in this study. MDJ is the guarantor.

Funding This work was supported by the Health Foundation (grant number 19-B0170), the Danish Rheumatism Association (grant number R175-A6011), the Aase and Ejnar Danielsens Foundation (grant number 19-10-0103 and 20-10-0176), the Association of Danish Physiotherapists Research Foundation and the Fogh-Nielsen Legacy, Aarhus University.

Competing interests All authors have completed the ICMJE uniform disclosure form at www.icmje.org/coi_disclosure.pdf and declare that we have no competing interests for the submitted work.

Patient consent for publication Not applicable.

Ethics approval The Central Denmark Region Committee on Health Research Ethics was notified of the study (case number 1-10-72-1-19), and the committee waived the request for formal approval. The Danish Data Protection Agency gave permission for the handling of personal data.

Provenance and peer review Not commissioned; externally peer reviewed.

Data availability statement Data are available upon reasonable request. Data are in the form of digital voice recordings of interviews, which were also transcribed verbatim into Word files. These data are stored in a password-protected research drive only accessible to the researchers of this study until 1 January 2023. Voice recordings contain identifiable data and will not be made available on request to maintain participant anonymity. Transcriptions with de-identified participant data may be made available on reasonable request.

Supplemental material This content has been supplied by the author(s). It has not been vetted by BMJ Publishing Group Limited (BMJ) and may not have been peer-reviewed. Any opinions or recommendations discussed are solely those of the author(s) and are not endorsed by BMJ. BMJ disclaims all liability and responsibility arising from any reliance placed on the content. Where the content includes any translated material, BMJ does not warrant the accuracy and reliability of the translations (including but not limited to local regulations, clinical guidelines, 
terminology, drug names and drug dosages), and is not responsible for any error and/or omissions arising from translation and adaptation or otherwise.

Open access This is an open access article distributed in accordance with the Creative Commons Attribution Non Commercial (CC BY-NC 4.0) license, which permits others to distribute, remix, adapt, build upon this work non-commercially, and license their derivative works on different terms, provided the original work is properly cited, appropriate credit is given, any changes made indicated, and the use is non-commercial. See: http://creativecommons.org/licenses/by-nc/4.0/.

\section{ORCID iDs}

Martin Dan Jorgensen http://orcid.org/0000-0001-8171-6964

Sarah Bournonville Frederiksen http://orcid.org/0000-0001-8746-581X

Julie Sandell Jacobsen http://orcid.org/0000-0002-3323-3631

\section{REFERENCES}

1 Jacobsen S, Rømer L, Søballe K. The other hip in unilateral hip dysplasia. Clin Orthop Relat Res 2006;446:239-46.

2 Shorter D, Hong T, Osborn DA. Cochrane review: screening programmes for developmental dysplasia of the hip in newborn infants. Evid Based Child Health 2013;8:11-54.

3 Clohisy JC, Ackerman J, Baca G, et al. Patient-Reported outcomes of periacetabular osteotomy from the prospective anchor cohort study. J Bone Joint Surg Am 2017;99:33-41.

4 Breidel KE, Coobs BR. Evaluating and managing acetabular dysplasia in adolescents and young adults. JAAPA 2019;32:32-7.

5 Nunley RM, Prather $\mathrm{H}$, Hunt D, et al. Clinical presentation of symptomatic acetabular dysplasia in skeletally mature patients. $J$ Bone Joint Surg Am 2011;93 Suppl 2:17-21.

6 Hartig-Andreasen C, Troelsen A, Thillemann TM, et al. What factors predict failure 4 to 12 years after periacetabular osteotomy? Clin Orthop Relat Res 2012;470:2978-87.

7 Troelsen A, Elmengaard B, Søballe K. A new minimally invasive transsartorial approach for periacetabular osteotomy. J Bone Joint Surg Am 2008;90:493-8.

8 Novais EN, Potter GD, Clohisy JC, et al. Obesity is a major risk factor for the development of complications after peri-acetabular osteotomy. Bone Joint J 2015;97-B:29-34.

9 Coobs BR, Xiong A, Clohisy JC. Contemporary concepts in the young adult hip patient: periacetabular osteotomy for hip dysplasia. J Arthroplasty 2015;30:1105-8.

10 Jakobsen SS, Overgaard S, Søballe K, et al. The interface between periacetabular osteotomy, hip arthroscopy and total hip arthroplasty in the young adult hip. EFORT Open Rev 2018;3:408-17.

11 Kuroda D, Maeyama A, Naito M, et al. Dynamic hip stability, strength and pain before and after hip abductor strengthening exercises for patients with dysplastic hips. Isokinet Exerc Sci 2013;21:95-100.

12 Mortensen L, Schultz J, Elsner A, et al. Progressive resistance training in patients with hip dysplasia: a feasibility study. J Rehabil Med 2018;50:751-8.

13 Sabaté E. Adherence to long-term therapies: evidence for action. Geneva: World Health Organization, 2003.

14 Martin LR, Williams SL, Haskard KB, et al. The challenge of patient adherence. Ther Clin Risk Manag 2005;1:189-99.

15 Gambling TS, Long A. Psycho-Social impact of developmental dysplasia of the hip and of differential access to early diagnosis and treatment: a narrative study of young adults. SAGE Open Med 2019;7:205031211983601.

16 Gambling TS, Long AF. Experiences of young women living with developmental dysplasia of the hip: insight into their experiences of surgery and recovery. Chronic IIIn 2013;9:16-28.

17 Gambling T, Long AF. An exploratory study of young women adjusting to developmental dysplasia of the hip and deciding on treatment choices. Chronic IIIn 2012;8:17-30.

18 Hampton SN, Nakonezny PA, Richard HM, et al. Pain catastrophizing, anxiety, and depression in hip pathology. Bone Joint J 2019;101-B:800-7.
19 Prather H, Creighton A, Sorenson C, et al. Anxiety and insomnia in young and middle-aged adult hip pain patients with and without femoroacetabular impingement and developmental hip dysplasia. Pm $R$ 2018;10:455-61.

20 Liu R, Li Y, Fan L, et al. Depression and anxiety before and after limb length discrepancy correction in patients with unilateral developmental dysplasia of the hip. J Psychosom Res 2015;79:574-9.

21 Podeszwa DA, Richard HM, Nguyen DC, et al. Preoperative psychological findings in adolescents undergoing hip preservation surgery. J Pediatr Orthop 2015;35:253-7.

22 Hurley M, Dickson K, Hallett R, et al. Exercise interventions and patient beliefs for people with hip, knee or hip and knee osteoarthritis: a mixed methods review. Cochrane Database Syst Rev 2018:4:CD010842.

23 I R de Oliveira B, Smith AJ, O'Sullivan PPB, et al. 'My hip is damaged': a qualitative investigation of people seeking care for persistent hip pain. Br J Sports Med 2020;54:858-65.

24 Simonÿ C, Specht K, Andersen IC, et al. A Ricoeur-inspired approach to interpret participant observations and interviews. Glob Qual Nurs Res 2018;5:233339361880739-10.

25 Dreyer PS, Pedersen BD. Distanciation in Ricoeur's theory of interpretation: narrations in a study of life experiences of living with chronic illness and home mechanical ventilation. Nurs Inq 2009;16:64-73.

26 Tong A, Sainsbury P, Craig J. Consolidated criteria for reporting qualitative research (COREQ): a 32-item checklist for interviews and focus groups. Int J Qual Health Care 2007;19:349-57.

27 Skou ST, Roos EM. Good Life with osteoArthritis in Denmark (GLA:D ${ }^{\mathrm{TM}}$ ): evidence-based education and supervised neuromuscular exercise delivered by certified physiotherapists nationwide. BMC Musculoskelet Disord 2017;18:72.

28 Mclntosh T, Hunter DJ, Royce S. Barriers to physical activity in obese adults: a rapid evidence assessment. J Res Nurs 2016;21:271-87.

29 Patton MQ. Qualitative research \& evaluation methods: integrating theory and practice. Thousand Oaks, CA: SAGE Publications, 2014.

30 Guest G, Bunce A, Johnson L. How many interviews are enough?: an experiment with data saturation and variability. Field Methods 2006;18:59-82.

31 Thorborg K, Hölmich P, Christensen R, et al. The Copenhagen hip and groin outcome score (HAGOS): development and validation according to the COSMIN checklist. Br J Sports Med 2011;45:478-91.

32 World Medical Association (WMA). Wma Declaration of Helsinki: ethical principles for medical research involving human subjects, 2018. Available: https://www.wma.net/policies-post/wmadeclaration-of-helsinki-ethical-principles-for-medical-researchinvolving-human-subjects/

33 Sturges JE, Hanrahan KJ. Comparing telephone and face-to-face qualitative interviewing: a research note. Qualitative Research 2004;4:107-18

34 Jacobsen JS, Nielsen DB, Sørensen $\mathrm{H}$, et al. Changes in walking and running in patients with hip dysplasia. Acta Orthop 2013;84:265-70.

35 Sørensen H, Nielsen DB, Jacobsen JS, et al. Isokinetic dynamometry and gait analysis reveal different hip joint status in patients with hip dysplasia. Hip Int 2019;29:215-21.

36 Reddy N, Martinez JR, Mulligan E, et al. Sleep quality and nocturnal pain in patients with femoroacetabular impingement and acetabular dysplasia. BMC Musculoskelet Disord 2020;21:134.

37 Jacobsen JS, Søballe K, Thorborg K, et al. Patient-Reported outcome and muscle-tendon pain after periacetabular osteotomy are related: 1-year follow-up in 82 patients with hip dysplasia. Acta Orthop 2019;90:40-5.

38 Smith EM. Telephone interviewing in healthcare research: a summary of the evidence. Nurse Res 2005;12:32-41.

39 McGovern RP, Martin RL, Kivlan BR, et al. Non-Operative management of individuals with non-arthritic hip pain: a literature review. Int J Sports Phys Ther 2019;14:135-47.

40 Wiberg G. Studies on dysplastic acetabula and congenital subluxation of the hip joint. Acta Orthop Scand 1939;58:1-132.

41 Tönnis D. Congenital dysplasia and dislocation of the hip in children and adults. Berlin/Heidelberg: Springer, 1987. 